\title{
CITY-PORT RELATIONSHIPS IN MALAGA, SPAIN: EFFECTS OF THE NEW PORT PROPOSALS ON URBAN TRAFFIC
}

\author{
ALEJANDRO L. GRINDLAY \& SERGIO MARTÍNEZ-HORNOS \\ Department of Urban and Regional Planning, University of Granada, Spain
}

\begin{abstract}
Traditionally, one of the most significant difficulties of the port-city relationship has been the issue of urban traffic hampering port operations and vice versa. The case of Malaga (Spain) is very special, given that its port, for historical reasons, is in close proximity to its urban centre. Port expansion towards deeper waters and its inherent increase in traffic flows has served to exacerbate the above problems. Thus, an ambitious project has been proposed to enable the transformation of underused port areas adjacent to the city for urban activities. Given the urban proximity, some areas of the port were required for urban integration as outlined in an agreement between the municipal and port authorities that was drafted in an urban plan revisited and modified in 2003. The subsequent transformation of wharves one and two has been very successful. However, in the current port development, there is vacant space alongside the new eastern dock, on which a maritime station for cruise ships has been installed. It is now proposed to enlarge this for 10,000 cruise passengers, and to create an area for a small marina and other facilities. This proposal also includes provision for a new 350-room hotel, in a remarkable tower building, and an aquarium. In order to evaluate the pressure of the new mobility flows that will be associated with the planned developments, a study of traffic and mobility has been carried out, analyzing, simulating, predicting and evaluating the degree of effects generated. The methodology, results and conclusions of this study are presented, as well as the measures and proposals for sustainable traffic management with regard to the new demands of the expected mobility flows. In conclusion, these flows can be perfectly accommodated by the road network in the new scenarios, generating an adequate and satisfactory relationship between port commercial activities and urban requirements.

Keywords: port-city relationships, urban traffic, port demands, traffic evaluation, Malaga, Spain.
\end{abstract}

\section{INTRODUCTION}

Considering the port-city relationship, urban areas have traditionally obstructed port expansion and developments, and the problems of urban traffic that have hampered port flows - and vice versa - has been one of the most significant difficulties. That is why, in the conventional port development schemes, port expansion is oriented in the opposite direction to the urban growth, or port facilities have even been completely moved to other locations. It can be seen in the city and port relationship at the main city-ports of the world, as Meyer [1], showed.

In the Spanish context, the case of Malaga is very special, given that its port, for historical reasons, is in close proximity to its urban centre, and their development possibilities have been limited by the intense urban growth along the coast around it as capital of the "Costa del Sol".

In this case all the stages of the port-city relationship, as have been described in general by Hoyle [2], can be verified. They have been adapted for the Mediterranean port cities of Andalusia as: unity, growth and distancing, isolation and separation and, finally, approach and integration [3]. This last stage will be enabled by the port expansion but, unlike other Mediterranean ports, in the case of Malaga, it has taken place towards deeper waters, due to the impossibility of occupying new stretches of its highly urbanized coast. So, at the end of the 1990s, the proposed ambitious port expansion enabled latterly the transformation of the 
most obsolete and underused port areas adjacent to the city for urban activities, in a city-port integration operation. Due to their urban centrality and in line with the transformations experienced in many other foreign and national ports, starting in Spain with Barcelona in 1985, thanks to an agreement between the municipal and port authorities, the port areas were to be integrated with the urban areas. It was embodied in a Special Urban Plan in 1998. This was modified in the face of social pressure in 2003. The urban operation to transform Quays One and Two took place between 2007 and 2011, creating a new urban waterfront with magnificent open spaces and new commercial and cultural facilities for the citizens' enjoyment of the sea [4]. Quay One neighbours the eastern dock (or "Dique de Levante") with a commercial and recreational area opened to the shipside, and Quay Two, adjoining it, displays a large park with a maritime museum, restaurants and a small cruise maritime station. The final result of this city-port operation has been very successful from the urban point of view, having recently been awarded the Regional Urbanism Award (2016) [5].

Despite the success of the urban operation, the inherent increase in traffic flows derived from the port expansion and freight traffic has served to exacerbate the above-mentioned problems generated by port transport in the urban area.

However, as with any real process, the port-city relationship carries on developing as port activity continues next to the city centre, threatening its success. In synthesis, the port-city relationships can be defined as "satisfactory" if urban and social demands and portcommercial demands are met in a satisfactory way for both counterparts [3], [4]. Table 1 summarizes this.

The last episode in the port development concerns the proposals alongside the new eastern dock located in an existing vacant space. In this area, a maritime station for cruise ships has been installed, and it is now proposed to enlarge this for 10,000 cruise passengers, and to create an area for a small marina and other facilities [6]. This proposal also includes provision for a new 350-room hotel, in a remarkable tower building [7], and an aquarium (Fig. 1).

These new uses and activities will generate new traffic flows affecting urban mobility and the conditions of urban traffic, mainly at the major east-west urban trunk road and scarcely on the central area of the city.

In order to evaluate the pressure of the new mobility flows that will be associated with the planned developments, a study of traffic and mobility has been carried out, analyzing, simulating, predicting and evaluating the degree of effects generated.

Table 1: Satisfactory port-city relationship reciprocal demands.

\begin{tabular}{|l|l|}
\hline Port and commercial & City and social \\
\hline $\begin{array}{l}\text { Good access conditions and high capacity } \\
\text { rail \& road connections. }\end{array}$ & $\begin{array}{l}\text { Limit barrier effect and to permeate port } \\
\text { areas. }\end{array}$ \\
\hline Expansion \& traffic growth possibilities. & Gain new public spaces and access to sea. \\
\hline Facilities development possibilities. & $\begin{array}{l}\text { Avoid negative impacts of port activity } \\
\text { (noise, pollution, heavy traffic, traffic } \\
\text { congestion, etc.). }\end{array}$ \\
\hline Avoid urban pressure. & Port uses compatible with urban life. \\
\hline
\end{tabular}




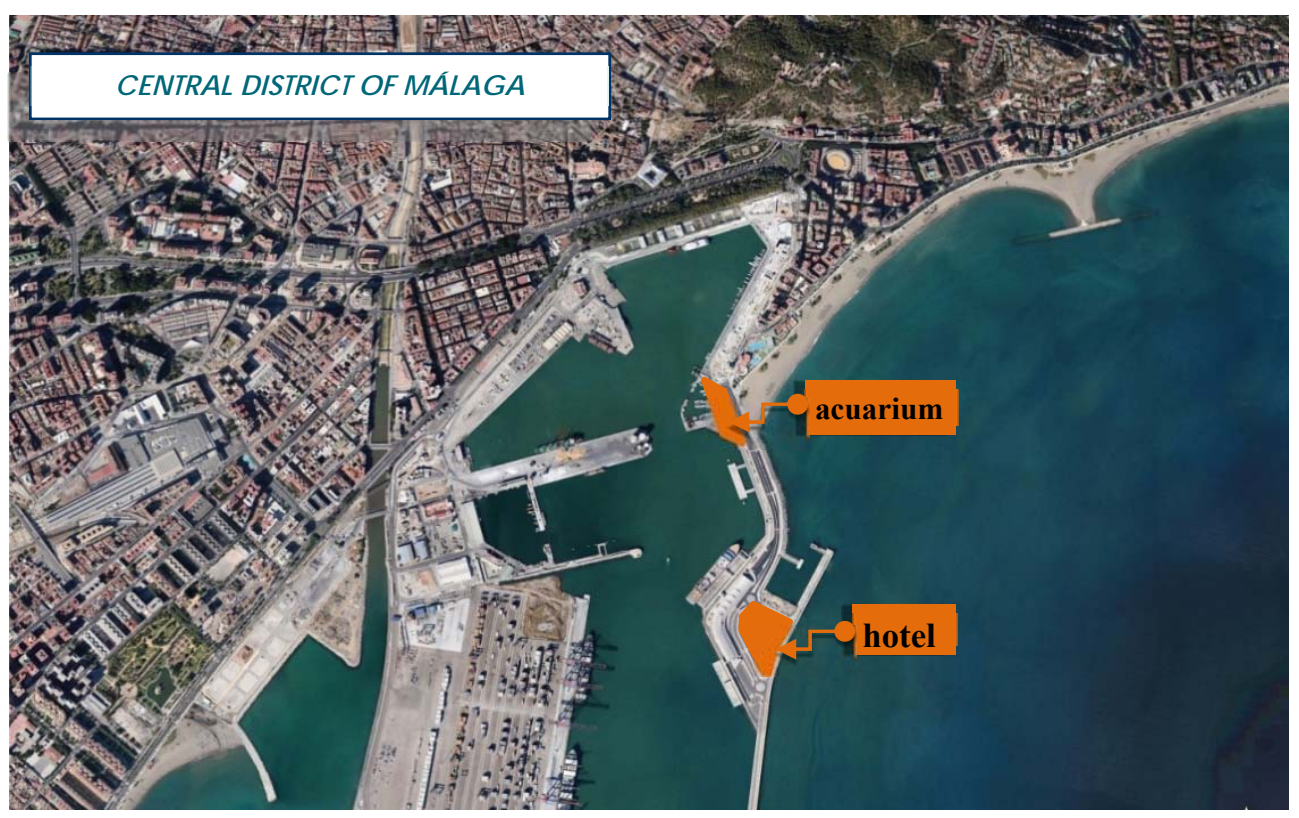

Figure 1: Localization of the new port proposals alongside the eastern dock.

Consequently, the methodology, results and conclusions of this study are now presented, as well as the measures and proposals for sustainable traffic management with regard to the new demands of the expected mobility flows.

\section{METHODOLOGY}

With the aim of evaluating the foreseen effects of the new flows from the proposed port developments on Malaga's road system, the methodology follows the steps of a conventional urban traffic study [8]: defining the study area, estimating the new demands, and modelling, simulating and predicting the future conditions. Initially three different scenarios (pessimistic, realistic and optimistic) were considered to study the effects on the main road sections and intersections, and to take into account the effects on the road space of the propagation of the aggregated model of demand through a global simulation.

Finally, the results are obtained showing the parameters of the simulated traffic flows in the different scenarios in the area of study. These traffic parameters are analyzed to determine the global effects and conditions, and the resulting delays.

This case study reveals how the management and treatment of new demands associated with new uses and centres of attraction / generation of trips can be evaluated and followed.

\subsection{Study area}

The area of influence on the city of Malaga of the new uses and planned developments alongside the eastern dock of the Port has been determined, based on the mobility patterns at the global level in the city and, particularly, on the traffic conditions in the main trunk roads, sections and crossings, within the affected road space [9]. The existing urban planning and the location of urban uses and activities have also been considered. 


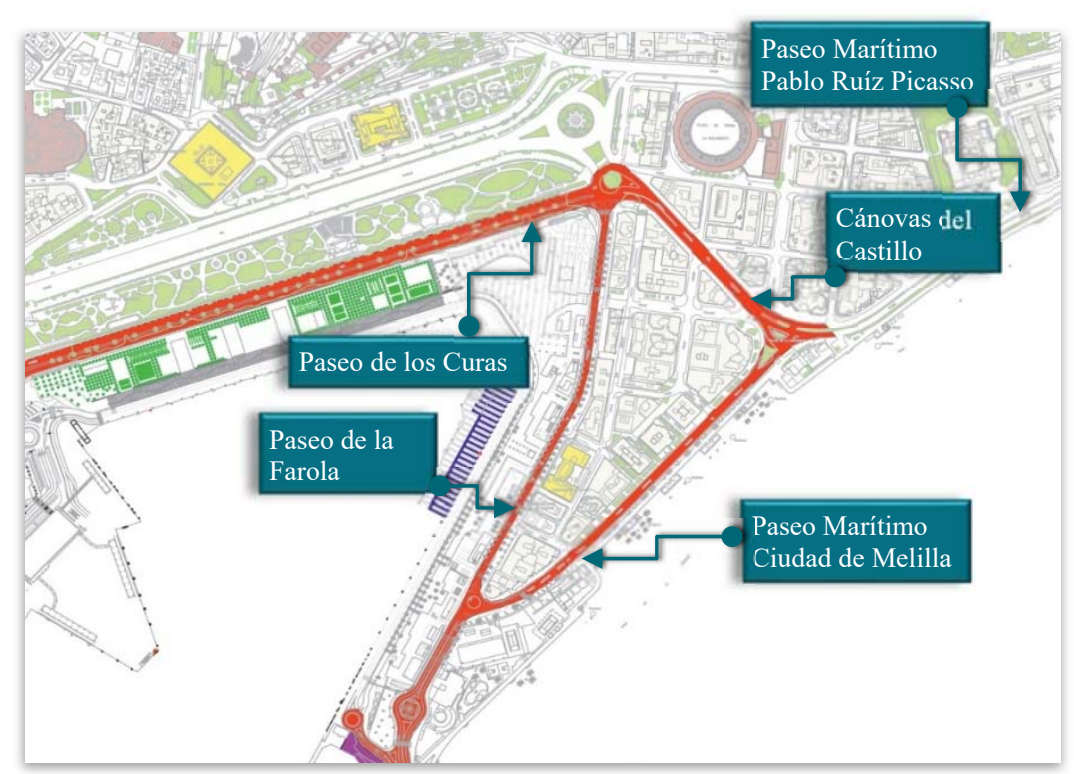

Figure 2: Study area: main city roads affected.

The need to verify the functionality and response of the road system after the new activities of the Port, as well as their effects, should be understood as they would be integrated in the city. Each new use and activity will affect the mobility directly at local and city levels.

The nearest urban sector contains several urban facilities and part of the general road system of the city, and a typical residential neighbourhood called the "Malagueta".

The considered area of analysis includes the internal road of the eastern dock and its connections with the main city roads affected by the increase in demand derived from the new uses to be implemented. These are: "Paseo de la Farola", "Paseo Marítimo", "Avenida de Cánovas del Castillo", "Paseo de los Curas", and the intersections which connect the above-mentioned roads (Fig. 2).

\subsection{New demands estimation}

The new mobility flows associated with the planned developments in the eastern dock have been estimated as follows:

Each activity has its own character and generates different mobility patterns in terms of intensity, duration and frequency. Therefore, the enlarged marine station for cruise ships, the new hotel and the aquarium have been considered.

The new traffic demands, generated and induced, number of trips and patterns, have been estimated quantitatively for these three major attractor centres and travels generators, indicating the temporal distribution throughout the day. Transport demand was modelled following the occupancy rate/loading factor of vehicles recommended by the "Practical guide for the development and implementation of sustainable urban mobility plans" [10], and latterly considered in the Sustainable Urban Mobility Plan of Malaga [11], developed, as in other urban areas in Andalusia, to change its model of mobility [12].

Firstly, the higher demand will be considered, associated with the pessimistic scenario. This will occur at peak hours during the landing times of cruise ships passengers. 
Consequently, the most unfavourable scenario will be estimated with the higher number of trips made for the peak days over the global mobility city flows.

This estimation is detailed for each new development.

\subsubsection{Cruise maritime station}

The cruise ship activity generates a great demand on road capacity due to the intense traffic given by the large number of travellers. There should be a distinction between passengers leaving Malaga and those who remain in the city. According to the latest statistics published by the Port Authority, the passenger traffic associated with cruises has reached the figure of 397,098 per year.

Since the average capacity of a cruise ship is around 2,000 passengers, for the scenario of maximum demand the potential coincidence of 5 cruise ships moored simultaneously can be considered. This is the most unfavourable scenario of coincidence that produces a total figure of 10,000 travellers.

The Operations Department of the Port Authority has confirmed that during the periods of 2010-2016 the figure of 10,000 passengers have been exceeded on only 5 days, and that is the figure which is fixed for the worst scenario. The adopted value of the last six years implies that it is above the $99.77 \%$ percentile of probability of occurrence.

According to the existing data, from this potential concentration of visitors in the cruise terminal, about $25 \%$ of them hire an organized tour and the remaining $75 \%$ do the day visit on their own. In the first case, for all visitor's transportation is included with the hired tour, usually by bus. With respect to the other $75 \%, 10 \%$ will access the city on foot through Quay One, $60 \%$ will use the port shuttles, going through the port inner road and take them to the pedestrian connection at Quay Two with "La Marina" square. From this point, there is direct walking access to the nearby historical and commercial centre of the city. The other $20 \%$ will go by taxi, and the remaining $10 \%$ will use the tourist train that runs through the port.

Specifically referring to the occupancy rate / loading factor of vehicles: average occupation Taxi/Rental vehicle is 3 people. Average occupancy considered by bus is 56 passengers.

Taking into account this bus average capacity of 56 passengers, the potential traffic of buses will be about 47 daily buses, with different possibilities of coincidence in certain times according to the simulated scenarios. From the experience of the tour operators of this number of buses, about 11 go towards Granada, 2 towards Cordoba, about 11 go to other municipalities of the "Costa del Sol" and 23 buses will visit the city of Malaga.

\subsubsection{Hotel}

The indexes of travel generation based on land uses are taken from the "Trip Generation Manual", produced by the Institute of Transportation Engineers [13]. Thus, for a hotel of about 350 rooms, the most unfavourable situation in terms of maximum demand, generates 252 rides at peak hour. For the Hotel, an average occupation of trips in private vehicle of 1.3 travellers has been considered.

\subsubsection{Aquarium}

The estimation of the demand generated from the Aquarium has been made comparatively with data of similar attractions in Spain. They are Oceanographic of Valencia, the Aquarium of Saragossa, the Aquarium of Gijon, the Aquarium of Seville and the estimation of visitors made for the future aquarium of Las Palmas de Gran Canaria. 
Table 2: New Demand Generated (NDG) by new activities.

\begin{tabular}{|c|c|c|c|}
\hline $\begin{array}{c}\text { Aggregation of } \\
\text { maximum demand } \\
\text { (veh./hour). }\end{array}$ & \multicolumn{3}{|c|}{$\begin{array}{c}\text { New Demand Generated Motorized } \\
\text { Wheeled Traffic by Activities }\end{array}$} \\
\cline { 2 - 4 } & $\begin{array}{c}\text { Cruise ships } \\
\text { Terminal }\end{array}$ & Hotel & Aquarium \\
\hline Total cars & 525 & 91 & 87 \\
\hline Total buses & 57 & 2 & 4 \\
\hline
\end{tabular}

Table 3: Total New Demand Generated (NDG) at rush hour for the most unfavourable scenario.

\begin{tabular}{|c|c|}
\hline $\begin{array}{c}\text { Aggregation model of } \\
\text { maximum demand } \\
\text { (veh./hour). }\end{array}$ & $\begin{array}{c}\text { New Demand Generated } \\
\text { Motorized Wheeled } \\
\text { Traffic (NDG) }\end{array}$ \\
\hline Total cars & 703 \\
\hline Total buses & 63 \\
\hline Total NDG (Veh./hour). & 766 \\
\hline Buses (\%) & 8 \\
\hline
\end{tabular}

This study gives a value for the demand of 600 visitors/hour, which is the maximum demand measured in the Aquarium of Seville in a day, which is $40 \%$ bigger than proposed in the eastern dock of the port.

For the Aquarium, an average occupation for private vehicle for leisure purposes of 2.3 travelers has been considered.

\subsubsection{Total new demand generated.}

After the estimation of the flows generated by the three new activities, these are combined to obtain the global demand of the journeys generated simultaneously, for the estimation of the worst-case scenario of motorized road traffic at rush hour. The other scenarios will be more favourable in terms of less traffic.

The most unfavourable urban traffic scenario is the one of maximum access solicitation in the eastern dock for the aggregated demand with the existing loads. The most unfavourable, as well as unlikely, situation has been considered. That is, the coincidence of space-time events, i.e. maximum demand for access to eastern dock with coincidence of access to hotel, aquarium and maximum cruise ships at the same time. Due to its topological configuration in the shape of a circuit with a single point of entry and exit, the routes are characterized by being pendulum type trips, access and departure, with a focus in origin and travel destination. It is necessary to consider the very low occurrence of the worst scenario taking place about only 4 hours per year.

\subsection{Modelling and simulation}

The study area route system is modelled using 104 control points. The inputs and outputs around the eastern dock road system are tested at these 104 control points defined for the calibration of the demand model (Fig. 3). 


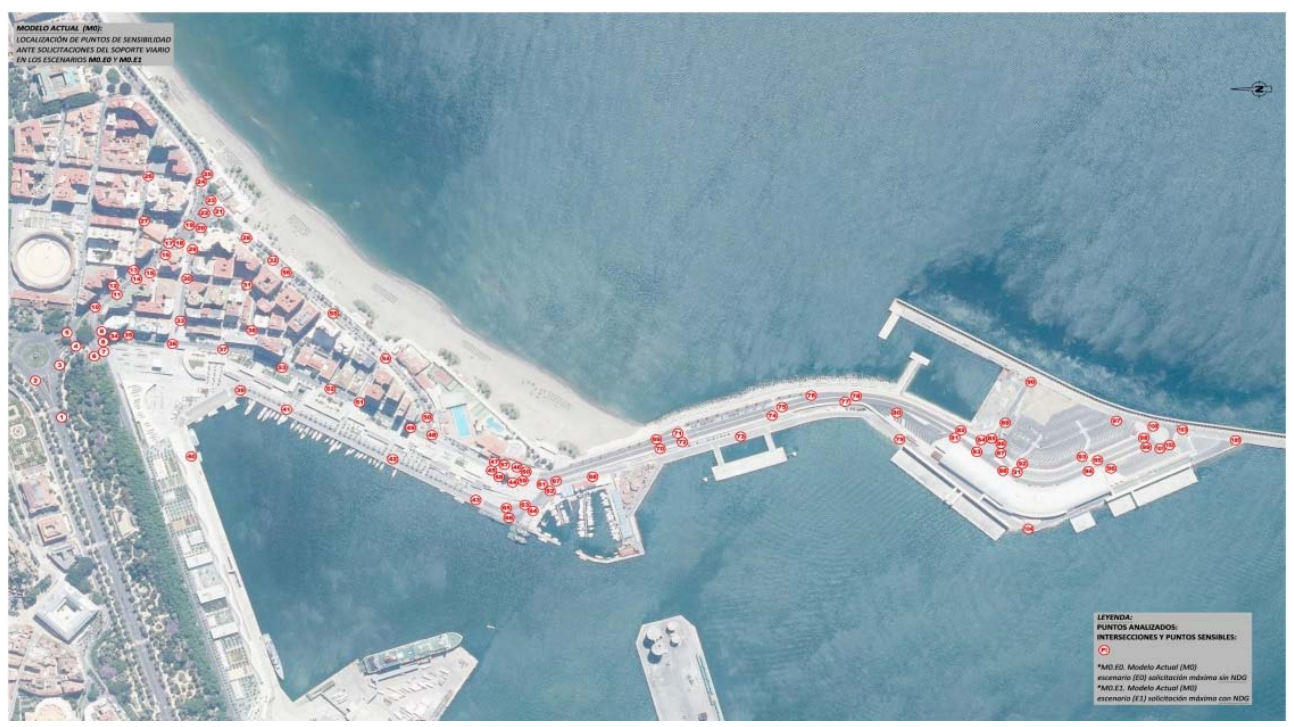

Figure 3: Model control points.

In the simulation of the new demand generated in relation to the city traffic, two scenarios are considered, the morning rush hour at 8:00 a.m. and the afternoon at 2:00 p.m.

The simulated rush hour scenarios considered are:

1. Maximum request scenario without the New Demand Generated (NDG) M0.E0.

2. Maximum request scenario with the New Demand Generated (NDG) M0.E1.

According to the methodology, for the scenario M0.E1 several factors were applied:

- The load factor is the safety factor of maximization of annual peak demand (Fmvd $=1.05$ ). It sets the state of loads above the average annual value supported by each control point.

- The safety factor for peak load maximization (Fmvp $=1.05)$.

- By the principle of Fmvd and Fmvp effects superimposition, the maximized load factor is set for supreme values $($ Fmvs $=$ Fmvd + Fmvp $=1.10)$. This factor establishes the value of increase of the loads for the prognosis of the most unfavourable trend scenario, that is, the maximum values that are established in the set of loads.

These safety coefficients were implemented in the aggregate model of demand with the NDG and considered with the traffic intensity data from the Mobility Area of Malaga town council and the simulation for the future scenario M0.E1 has been made.

The functionality and level of service for each control point of the model with the traffic parameters expressed within urban traffic flow patterns have been defined theoretically by the Highway Capacity Manual (HCM) [14].

All the physical parameters of the road network of the study area are entered (M0) and the traffic parameters of transitory character are assigned in each control point (104) for the different scenarios, current (E0) and future (E1). Then the formal conditions are obtained that 
are imported in the model of analysis and on which the modelling is carried out that determines the functional conditions according to levels of solicitations and sensitivity to the loads that support in service for each one of the sections, nodes and movements that have been analyzed.

The simulation of the road model for the scenarios and operational conditions of solicitation has been carried out by the commercial software SYNCHRO 8.0 Calculation Package [15], obtaining the future circulation distribution.

\section{RESULTS}

The results show the degree of the effects for the aggregated model of new traffic demands implemented in the road space obtained from the simulation with the new general patterns of the urban mobility in the City of Malaga. It is possible to evaluate the capacity of the road system, it response to the new demands and the requirements of road management in the study area with an integral character.

The simulation generates reports of results of functionality and level of service for each control point with the expressed traffic parameters. This simulation output has been processed graphically to improve its understanding, known as "Traffic Spatial-Temporal Model Scene" (TSTM Scene). A series of figures identified with the control point for the different sections of streets, intersections and nodes, which have been specifically studied, have been prepared. This graphical treatment of the physical data of the roads and traffic parameters includes the spatial location of the control point, intensity/capacity relationship and the consequent level of service (Fig. 4).

The graphical reports of functional results and level of service for each point with the traffic parameters expressed with urban traffic flow patterns, which have been previously defined theoretically by the HCM, are interpreted locally and globally with the delays that occur in rush hour in the simulated scenarios.

The results show a clear reading on the behaviour of the new mobility patterns at a global level in the City of Malaga and specifically on the traffic conditions on the main trunk roads, sections and crossings within the area of influence affected after the implementation of the new developments in the eastern dock of the port.

Particularly in the analyzed scenario, the levels of service present more restrictive conditions at the entrance of the "Paseo de la Farola" and the exit of the "Paseo Ciudad de Melilla".

Most of the eastern dock inner road presents sufficient operability in the scenarios of maximum solicitation $\mathrm{M} 0 \mathrm{E} 1.8 \mathrm{H}$ and $\mathrm{M} 0 \mathrm{E} 1.14 \mathrm{H}$. The delays in the connections with the EastWest roads of the city are increased, but they are acceptable at the global level.

The two ratios analyzed, the simulation model and the current situation, guarantee the viability of the scenarios analyzed in the hours of maximum demand which, when compared to the total annual volume, are not very representative. For the understanding of the global incidence of traffic increasing due to generated demand the final results are the following:

- M0.E0 scenario from 8 a.m. to 2 p.m. shows an increase in road occupancy ratios at the global level of $1.1 \%$.

- M0.E1 scenario from 8 a.m. to 2 p.m. there is an increase in road occupancy ratios at the global level of $1.7 \%$.

- M0.E0 to M0.E1 scenario at 8 a.m. shows an increase in occupancy ratios of the road space at the global level of $11.7 \%$.

- M0.E0 to M0.E1 scenario at 2 p.m. registers an increase in the occupancy ratio of the road space at a global level of $12.3 \%$. 


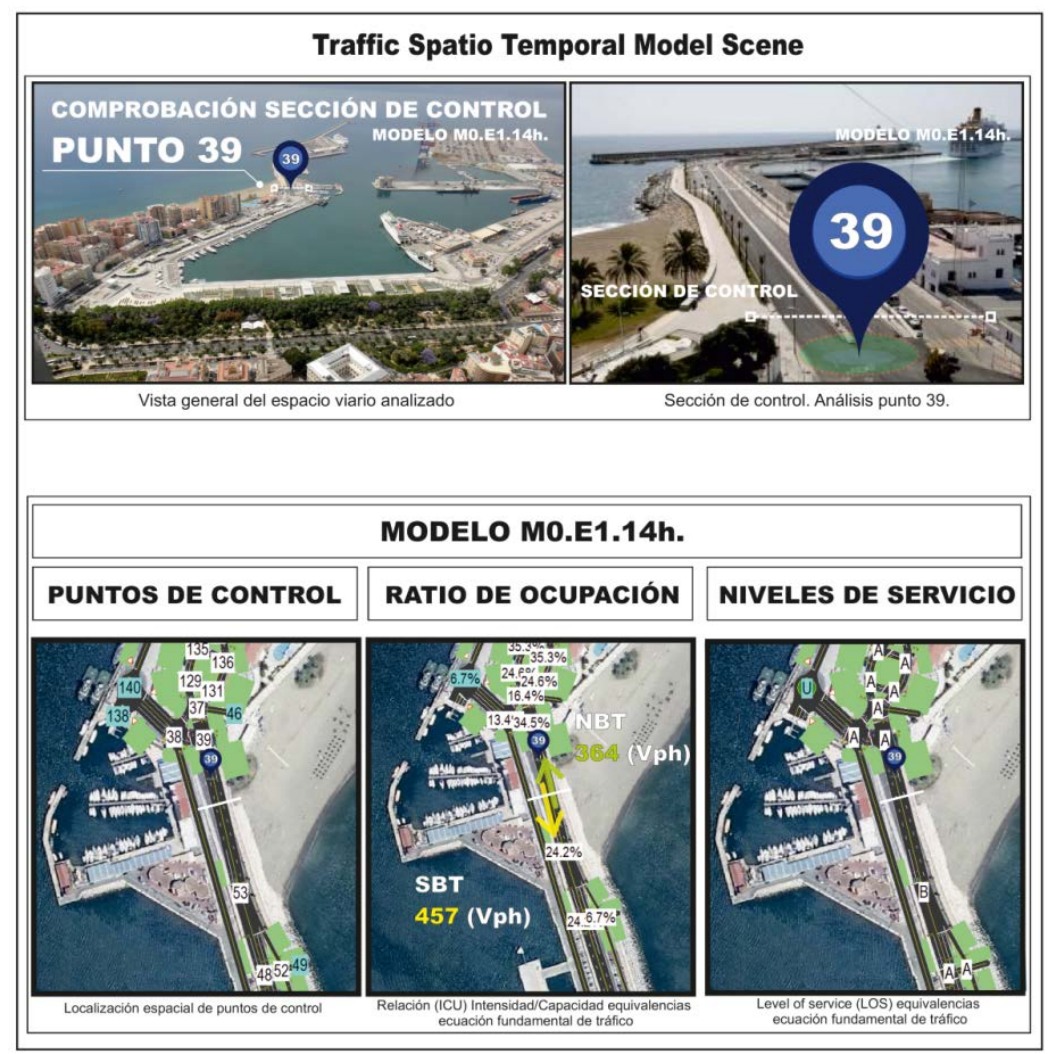

Figure 4: Example of graphical report (TSTM Scene).

The total effects measured on the whole of the analyzed roads in the study area present an incremental variation within a small range in the main trunk roads at city level: an increase of $8.2 \%$ is registered, ranging from $4.3 \%$ for "Av. Cánovas del Castillo" in the East direction in the M0.E1.8H scenario, up to $12.5 \%$ for "Av. Cánovas del Castillo" in the West direction in the M0.E1.14H scenario.

The major global impact of the new demand generated translated into effective increases of travel time for the users is in the section of "Av. Cánovas del Castillo" towards the west from the exit of "Paseo Ciudad de Melilla" through "Paseo de los Curas", where the average increase in the service delay for a trip on the M0.E1.14H scenario is 53 seconds towards the city centre. Similarly, for the case of lesser degree of effect to the user is at the section of "Av. Cánovas del Castillo" towards the east from the access to the "Paseo de la Farola" through the exit by "Paseo Ciudad de Melilla", where the average increase in the delay of service for a trip on the stage M0.E1.8H is 17 seconds towards the neighbourhood of "La Caleta". A typical user of the main road network would be delayed by only 80 seconds in total to cross the East - West trunk road in this less favourable situation. In the "Paseo de los Curas", a typical user would only be delayed 31 seconds towards the west direction at 8 a.m. and 25 seconds towards the east at peak time at 2 p.m. for the stage M0.E1.

Given the acceptable results for the most unfavourable scenario (pessimistic) the simulation for the other scenarios (realistic and optimistic) has been considered unnecessary, 
because these intermediate scenarios will present better circulation conditions, and shorter time increments than M0.E1.

This summary of the increase of loads in percentage at the global level allows an evaluation and quantification of the degree of effect and impact of the new traffic conditions in the port and in the area of influence at city level.

The graphical report for the diagnosis of the predicted scenario allows a reading of the degree of operability and functionality for the future scenarios in the eastern dock, by control point, or by group of control points.

The simulation results show the operations that will be carried out, or simply allow a definition of the most effective ways to carry out any route or distribution of access or departure in the study area.

\section{DISCUSSION AND CONCLUSIONS}

The consideration of the previous results showing the future scenario envisaged in the eastern dock permit the following discussion and conclusions:

1. The degree of the effects of the proposed developments has been expressed numerically, translated in general increments in times of service for the users. It presents acceptable delays and, transformed into the classic parameters of urban traffic, the convergence and continuity in the general patterns for the mobility model is confirmed. The conditions for mobility will be manageable in the scenario predicted M0E1.

2. The new demands generated will not cause major congestion along the main East-West road, nor will access time be greatly increased at the entrance and exit from the principal roadways that connect the eastern dock, and will be absorbed by the road of the study area without affecting the central areas of the city.

3. The degree of effect and impact for the predicted scenario has been evaluated and quantified for the most critical level of service, in a scenario of very low occurrence, i.e., its functionality in the event of the day of maximum solicitation has been verified.

4. The road space will respond with functionality and operational capability. The demands will be managed without major congestion and with habitual problems associated with the light increase of travel times.

5. The study demonstrates that the degree of representativeness of the new demand generated in comparison with the existing traffic currently registered by the Area of Mobility of Malaga city council is small and of a second-order. Although it is not negligible, so that the new demands will prove to be less relevant and influential in the general patterns of East-West mobility at the city level, maintaining in future management patterns of continuity.

6. The results show that there is sufficient capacity in the road space to assume the new scenario of loads and to maintain the convergent mobility patterns with the current ones without congestion. The simulation of the model replicates for the future scenario a lightly affected circulation and with marked continuity behaviours to those that currently occur daily in this major East-West connection of the City of Malaga.

7. At the local level, intensity values are recorded, which in some of the analyzed intersections increase occupancy ratios, delay times, and queue lengths, but there are no oscillations in the flows, which propagate serious interference and that put at risk the operational capacity of the road system in its main trunk of "Av. Cánovas 
del Castillo - Paseo Los Curas - General Torrijos", and its connections with "Paseo de la Farola" and "Paseo Ciudad del Melilla". It is shown that they will be acceptable in the rush hour trips on the day tested as the worst scenario. At these points, the congestion ratios increase and the flows will be a little denser, however this situation is transient throughout the day. It is necessary to appreciate that the daily points are reached during a very low total of hours over a year (4), and the scenario of maximum load has the probability to occur in only one day of the year.

8. The results establish that the new intended port uses that will be developed and the new demands associated will be assumed with enough capacity by the whole of the road system and its intersections, presenting functional operability with viable character for the management in the analyzed control points.

In conclusion, these new flows can perfectly be accommodated by the road network in the new scenarios, generating an adequate and satisfactory relationship between the port commercial activities and the urban requirements.

This study will serve as a support element for the decision in the planning procedures, the public information processes, and for the projects' final approval by the various administrations and governing bodies. It will also serve as an element, from a technical perspective, to help the progress for the management of collaboration formulas between Port Authority and Town Council, in the field of mobility and urbanism.

\section{ACKNOWLEDGEMENTS}

The authors of this paper acknowledge the help of Malaga Port Authority (Autoridad Portuaria de Málaga and the Mobility Area of the Malaga town council (Área de Movilidad del Ayuntamiento de Málaga. The authors of this paper also acknowledge the anonymous reviewer of this manuscript for their helpful questions and comments.

\section{REFERENCES}

[1] Meyer, H., City and Port:Urban Planning as a Cultural Venture in London, Barcelona, New York and Rotterdam, International Books: Rotterdam, 1999.

[2] Hoyle, B.S., Development dynamics at the port-city interface. Revitalising the waterfront. International dimension of dockland redevelopment, eds. Hoyle, B.S., Pinder, D.A. \& Husain, M.S., John Wiley \& Sons: Chichester, pp. 3-19, 1994.

[3] Grindlay Moreno, A.L., Puerto y Ciudad en Andalucía Oriental, Editorial Universidad de Granada: Granada, 2008.

[4] Grindlay Moreno, A.L., Ciudades y puertos. Revista Ciudades Instituto Universitario de Urbanistica. Universidad de Valladolid, 11, pp. 53-80, 2008.

[5] Premio Andalucía de Urbanismo a la actuación ejecutada: Puerto de Málaga. Online, https://www.juntadeandalucia.es/medioambiente/site/portalweb/menuitem.6ffc $7 f 4 a 44$ 59b86a1daa5c105510e1 ca/?vgnextoid=a64d85ccc0ad7510 VgnVCM1000001325e50a RCRD\&vgnextchannel=319aa8e0c8c0e210VgnVCM10000055011 eacRCRD.

[6] Autoridad Portuaria de Málaga, http://www.puertomalaga.com/web/guest/home.

[7] HOTEL MALAGA-PORT, http://www.hotelmalagaport.com/.

[8] Kraemer C. \& Pardillo J.M., Ingeniería de Carreteras, McGraw Hill: Madrid, 2003.

[9] Área de Movilidad del Ayuntamiento de Málaga, http://movilidad.malaga.eu/.

[10] Instituto para la Diversificación y Ahorro de la Energía, Guía práctica para la elaboración e implantación de planes de movilidad urbana sostenible, IDAE: Madrid, 2006.

[11] Ayuntamiento de Málaga, Plan Municipal de Movilidad Sostenible, Málaga, 2011. 
[12] Grindlay, A. L., Molero, E., Miralles-Guash, C. \& Lizarraga, C., Environmental impacts of everyday mobility in Andalusia (Spain). Towards a sustainable scenario? WIT Transactions on Ecology and the Environment, 194, WIT Press: Southampton and Boston, pp. 373-384, 2015.

[13] Institute of Transportation Engineers, Trip Generation Manual, ITE: Washington, 2012.

[14] Transportation Research Board, Highway Capacity Manual 2010, TRB: Washington, 2010.

[15] Trafficware SYNCHRO 8.0, http://www.trafficware.com/synchro-store.html. 